\title{
Relevant Glycoconjugates on the Surface of Trypanosoma cruzi
}

\author{
Walter Colli/ ${ }^{+}$, Maria Júlia Manso Alves \\ Departamento de Bioquímica, Instituto de Química, Universidade de São Paulo, Caixa Postal 26077, 05599-970 \\ São Paulo, SP, Brazil \\ Key words: Trypanosoma cruzi - Tc-85 - galactofuranose - adhesion - laminin - lipopeptido phosphoglycan - \\ extracellular matrix
}

\begin{abstract}
Although Chagas disease has been discovered 90 years ago, only after 1970 substantial progress has been made in the knowledge of molecular aspects of the host-parasite interaction. The amount of information gathered in the past 30 years was considerable, making it virtually impossible to cover all aspects of the biochemistry and molecular biology of the Trypanosoma cruzi, the etiologic agent of the disease. T. cruzi colonizes different habitats, from the intestinal tract of an insect to the cytoplasm of a mammalian cell, with a brief passage by the blood of the vertebrate host. An adaptation of the parasite to these different environments should occur and, consequently, differences in the composition of the plasma membrane should be expected among the parasite stages. In fact, in each parasite stage, molecules belonging to the surface membrane are the ones most probably involved in interaction with the hosts. In the vertebrate side of the infective cycle, the parasite has to leave the blood by crossing the capillary walls, the basal laminae and the extracellular matrix before encountering receptors located on the host cell plasma membrane. In the invertebrate phase of the cycle, epimastigotes must attach to the perimicrovillar membrane of the reduviid intestine in order to get prepared to differentiate to metacyclic trypomastigotes.

This review will cover mainly the evolution of knowledge which occurred with the parasite macromolecular structures residing in the plasma membrane and originally described by our laboratory.
\end{abstract}

The manuscripts from our laboratory mentioned in this article have been supported by Fapesp, CNPq (program PADCT), WHO and Finep. The authors are fellows of CNPq.

${ }^{+}$Corresponding author. Fax: +55-11-815.5579. E-mail: walcolli@usp.br

Received 9 June 1999

Accepted 9 August 1999
In fact, by extracting epimastigote forms with phenol it was possible to separate in polyacrylamide gels four bands developed by the Schiff reagent that were called bands A, B, C, and D (Alves \& Colli 1975). Band D was baptized as lipopeptido phosphoglycan (LPPG) (Lederkremer et al. 1976), and more recently T. cruzi Type-1 GIPL (Ferguson 1997), and bands A, B, C have been shown to be compounds which are the main sialic acid acceptors on T. cruzi membranes, including the now well studied mucins (Acosta Serrano et al. 1995). In addition, trypomastigotes have on their surface a family of glycoproteins (Abuin et al. 1989) probably involved in parasite interiorization (Alves et al. 1986) and adhesion (Giordano et al. 1994, 1999, Alves 1996) which have been collectively called Tc-85 (Katzin \& Colli 1983).

Excellent reviews on related issues were recently published on surface receptors and transporters of trypanosomatids, including the glucose transporter (Tetaud et al. 1997, Borst \& Fairlamb 1998) and trans-sialidase (Cross \& Takle 1993, Colli 1993, Schenkman et al. 1994).

\section{LPPG AND GALACTOFURANOSE}

Phenolic extraction of epimastigote forms led to the identification of four glycoconjugates stained by the Schiff reagent and called bands A, B, C, and D (Alves \& Colli 1975). Extraction of that complex mixture with chloroform:methanol:water (10:10:3) allowed the purification of band D (Lederkremer et al. 1976). The latter contained mannose, galactose, glucosamine, phosphorus, fatty acids, inositol and long chain alcoholic bases. Due this complex composition the substance was baptized as LPPG. The term peptide was introduced because a faint reaction with dyes specific for proteins was observed. Later it was demonstrated that single aminoacids or even dipeptides may be bound to the sugar residues by ester linkages (Lederkremer et al. 1985a).

The main fatty acids are palmitic and lignoceric acids with the latter bound as amide to sphingosine bases forming ceramides (Lederkremer et al. 1977). 
The binding of an inositol-phosphate group to the ceramide was demonstrated in our laboratory (Lederkremer et al. 1978). By 1978, the basic structural feature of a glucosamine-inositol-phosphate linked to a ceramide in LPPG was known and it was also demonstrated that LPPG was the major component of the epimastigote form plasma membrane (Alves et al. 1979).

Our laboratory also demonstrated that galactose is quantitatively liberated from LPPG by diluted trifluoroacetic acid under conditions that only liberate furanoic rings (Lederkremer et al. 1980). That sugar is easily attacked by metaperiodate eliminating carbon 6 and oxidizing carbon 5. If that treatment is followed by compound reduction with tritiated sodium borohydride the final product will be a labeled L-arabinose. These experiments have been made and the existence of terminal galactofuranose residues in a protozoan glycoconjugate was demonstrated for the first time in the literature (Lederkremer et al. 1980). Results pointing to the same direction were also found by Gorin et al. (1981) who described the existence of furanoic galactose bound to the three position of [1-2] bound mannose residues (Mendonça-Previato et al. 1983, Lederkremer et al. 1985b). It took 10 years to elucidate the structure of the oligosaccharide from LPPG. Previous studies had shown the presence of mannose [1-2] and [1-6] bound to the ceramide fraction (Lederkremer et al. 1985b) and, finally, the complete structure was published by two independent groups (Previato et al. 1990, Lederkremer et al. 1990, 1991).

More recently the glycoinositolphospholipids (GIPLs) received great attention since it was demonstrated that they act as anchors of proteins on the eukaryotic cell membrane and, for instance, of a phosphosaccharide in Leishmania (Turco \& Descoteaux 1992).

Figure shows the structure of LPPG as compared to glycophosphatidilinositol anchors (Cross 1990) and the lipophosphoglycan (LPG) from Leishmania donovani (Turco et al. 1989), the latter with galactofuranose internal to the oligosaccharide chain. In anchors, a residue of aspartic acid from the protein is linked to an ethanolamine phosphate residue (Cross 1990). LPPG does not contain ethanolamine phosphate but the phosphonic (carbon-phosphorus bond) analogs 2-aminoethylphosphonic acid (Ferguson et al. 1982, Lederkremer et al. 1985a, Lederkremer et al. 1991) and 2-amino-3-phosphopropionic acid (Lederkremer et al. 1985a).

Other GIPLs found in Leishmania, as well as LPG, contain a glycerolipid instead of a ceramide in the apolar portion (McConville et al. 1990, 1993). These GIPLs, as well as others described in Leptomonas samueli (Previato et al. 1992) and
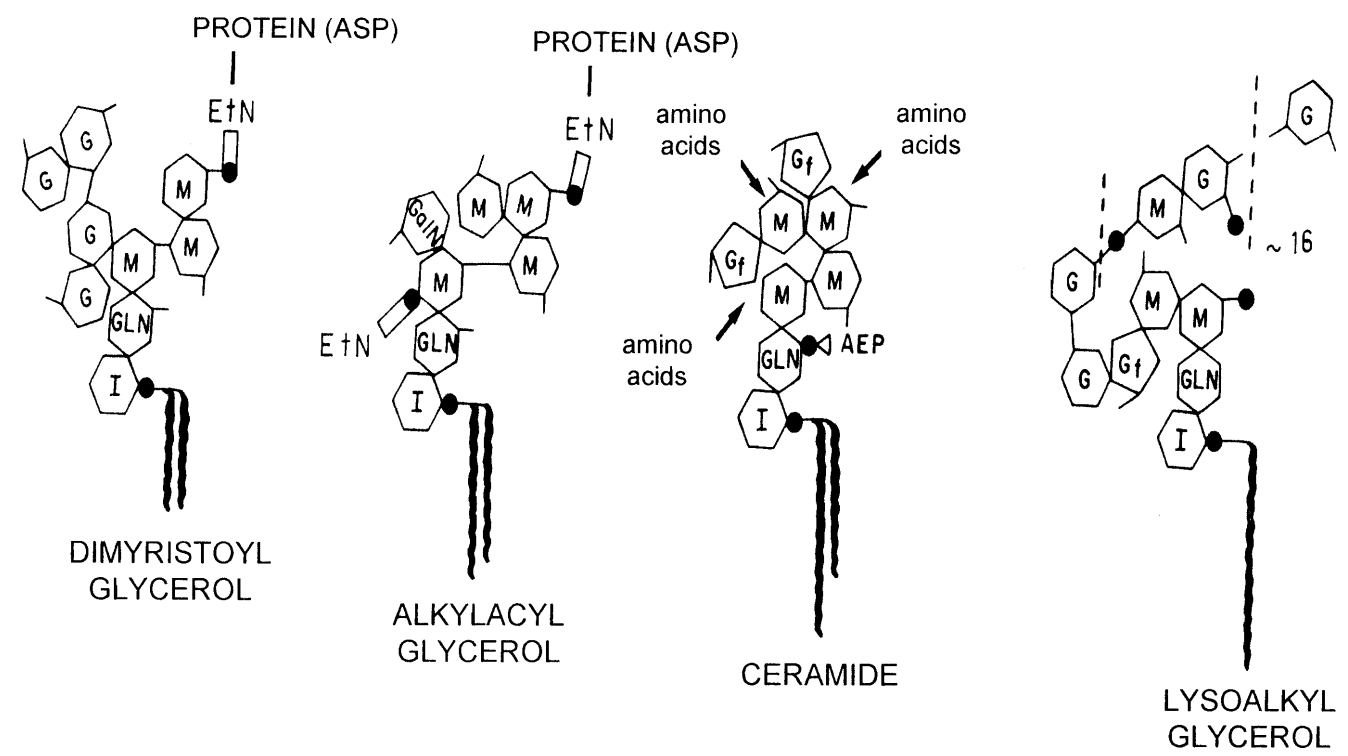

Structure of four glycoinositolphospholipids. VSG and THY-1 are, respectively, anchors from VSG (Trypanosoma brucei) and THY-1 (rat brain). LPPG is the lipopeptidophosphoglycan (T. cruzi) and LPG is lipophosphoglycan (Leishmania). G: galactose; M: mannose; I: inositol; GLN: glucosamine, GalN: galactosamine; EtN: ethanolamine; AEP: aminoethylphosphonic acid; $\mathrm{G}_{\mathrm{f}}$ : galactofuranose; ASP: aspartic acid; $(\bullet)$ phosphate. 
TABLE I

Galactofuranose-containing structures in some trypanosomatids

\begin{tabular}{llc}
\hline Organism & Structures & Ref. \\
\hline GPI-simile structures & & Lipopeptidophosphoglycan (LPPG) \\
Trypanosoma cruzi (epimastigotes) & GIPL-A and GIPL-B & a-d \\
Trypanosoma cruzi (epimastigotes) & Lipophosphoglycan (LPG) & $\mathrm{e}$ \\
Leishmania donovani and Leishmania sp. & GIPL-1, GIPL-2, GIPL-3, GIPL-A, LPGp & $\mathrm{f}, \mathrm{g}$ \\
Leishmania major & GIPL-2, GIPL-3, LPGp & $\mathrm{h}$ \\
Leishmania mexicana & GIPL & $\mathrm{i}$ \\
Leptomonas samueli & GIPL & $\mathrm{j}$ \\
Endotrypanum schaudinni & GIPL & $\mathrm{k}$ \\
Leishmania adleri & & 1 \\
Glycoproteins & Surface glycoproteins (80-90 kDa) & $\mathrm{m}$ \\
Trypanosoma cruzi (trypomastigotes) & Mucins & $\mathrm{n}, \mathrm{o}, \mathrm{p}$ \\
Trypanosoma cruzi & N-linked glycoproteins & $\mathrm{q}$ \\
Leptomonas samueli & N-linked glycoproteins & $\mathrm{q}$ \\
Herpetomonas samuelpessoai & N-linked glycoproteins & $\mathrm{r}$ \\
Erithidia fasciculata and $C$. harmosa & N-linked glycoproteins & $\mathrm{s}$ \\
\hline
\end{tabular}

a: Lederkremer et al. 1976; b: Lederkremer et al. 1980; c: Lederkremer et al. 1991; d: Previato et al. 1990; e: Lederkremer et al. 1993; f: Turco et al. 1989; g: Turco \& Descoteaux 1992; h: McConville et al. 1990; i: McConville \& Ferguson 1993; j: Previato et al. 1992; k: Previato et al. 1993; 1: Previato et al. 1997; m: Arruda et al. 1989; n: Previato et al. 1994; o: Previato et al. 1995; p: Acosta-Serrano et al.1995; q: Moraes et al. 1988; r: Mendelzon \& Parodi 1986; s: Merello et al. 1995.

Endotrypanum schaudinni (Previato et al. 1993), the latter with ceramide in the apolar portion, contain terminal galactofuranose (Table I).

LPPG is routinely isolated from parasites in the stationary phase of growth (4-5 days). However, two GIPLs can be isolated from cells in exponential growth. These lipids differ in the apolar portion since one contains hexadecylpalmitoyl glycerol bound to a galactofuranose-containing glycan, whereas the other contains ceramide. Notwithstanding, in these cases, $20 \%$ of the galactose residues are in the pyranoic configuration (Lederkremer et al. 1993).

These findings pose several unresolved problems of crucial importance: (1) would the synthesis of these compounds be made from a common precursor, with posterior remodelling of the lipid portion or, in other words, could a glycerolipid be substituted for by a ceramide in one single reaction step, or vice-versa? (2) or would the synthesis of GIPLs be made entirely de novo accompanying stages transitions? (3) could pyranoic galactose rings be transformed in furanoic galactose residues after incorporation inside an oligosaccharide chain? or (4) alternatively, would the latter be incorporated into a macromolecule via a UDP-Gal ${ }_{f}$ precursor? Nassau et al. (1996), have been able to obtain clones of UDP-galactopyranose mutase from E. coli $\mathrm{K}-12$ capable to convert reversibly $\mathrm{UDP}_{-\mathrm{gal}_{p}}$ to UDP-gal $f$ with the equilibrium fa- voring the formation of the pyranoic compound. More recently, mutases have been cloned in Klebsiella pneumoniae (Koplin et al. 1997) and Mycobacteria (Weston et al. 1998). The search of that enzyme in $T$. cruzi is imperative since the design of inhibitors to block its activity may render a very specific chemoterapeutic agent since mammalians do not seem to possess galactofuranose (cf. Lederkremer \& Colli 1995).

It is interesting to note that in all GIPLs, furanoic galactose, when present, is bound to an $\alpha$-D-mannose by a $\beta 1 \rightarrow 3$ bond, as a non reducing terminal sugar - as in LPPG (Lederkremer et al. 1985b, 1991, Previato et al. 1990, Carreira et al. 1996) - or as an internal unit inside an oligosaccharide chain - as in Leishmania LPG (Turco \& Descoteaux 1992). That specificity suggests the existence of a $\beta(1-3)$ galactofuranosyltransferase for biosynthesis and a $\beta(1-3)$ galactofuranosyl hydrolase for degradation. Evidently, the elucidation of the metabolic pathways involving this sugar is very important for the development of chemotherapeutic agents without affecting the host.

Would the function of LPPG be merely structural? One should not forget that this molecule also exists in cell cultured trypomastigotes, although 10fold less represented (Golgher et al. 1993). In Leishmania, LPG is important in parasite adhesion to the insect intestinal cells during parasite differentiation (Pimenta et al. 1994, Butcher et al. 1996). 
In collaboration with several groups one of us (WC) is trying to show the active participation of LPPG in the binding of epimastigotes to the perimicrovillar membrane of the reduviid insect.

LPPG was found to block in vitro CD4(+) and CD8(+) T cell induced mitogenesis and to reduce secretion of IL-2 among others. These and other features seem to be due to the ceramide moiety rather than the phosphoinositol oligosaccharides (Gomes et al. 1996). Using macrophages it was possible to show that the ceramide moiety of LPPG is able to induce in vitro fluid phase endocytosis as well as apoptosis in the presence of IFN- $\gamma$ and independently of nitric oxide secretion. Release of viable parasites from infected macrophages was augmented in the presence of ceramide and IFN- $\gamma$. These observations suggest a role for the ceramide portion of LPPG in spite of the fact that similar results can be obtained with synthetic ceramides (Freire-de-Lima et al. 1998).

A serum elicited in rabbits against LPPG has shown, by immunoelectronmicroscopy, a homogeneous distribution on the surface of epimastigotes allowing to determine the existence of $1-1.5 \times 10^{7}$ molecules of LPPG on the epimastigote surface (Golgher et al. 1993), a measurement which is in accordance with estimates made by other methods (Lederkremer et al. 1991). An average of $10^{6}$ molecules was found in trypomastigotes but labeling was heterogeneous and only $15 \%$ of the trypomastigote forms were found labeled. There was an intense labeling of vesicles in the cytoplasm from both parasite stages (Golgher et al. 1993). It has been found that sera from chronic chagasic patients contain antibodies to LPPG mainly directed against galactofuranose (Golgher et al. 1993) but they did not protect against a parasite challenge (Travassos \& Almeida 1993).

Terminal furanoic galactose was also found in mannose-rich oligosaccharides in the lower trypanosomatids Crithidia fasciculata e $C$. harmosa (Mendelzon \& Parodi 1986), L. samueli e H. samuelpessoai (Moraes et al. 1988). This residue can be liberated by a $\beta$-galactofuranosidase from Penicillium fellutanum, but the bond position has not been determined. Galactofuranosyl residues have also been described in $\mathrm{N}$-linked chains of $80-90 \mathrm{kDa}$ glycoproteins from the trypomastigote forms (Arruda et al. 1989). Most probably, the latter were the mucin-like glycoproteins that were extensively studies in the past seven years (see below).

One would expect that galactofuranose, being absent from mammalian glycoconjugates, should be highly antigenic and, in fact, terminal $\beta$-Dgalactofuranose epitopes are recognized by antibodies elicited by the 80-90 kDa glycoproteins of
T. cruzi trypomastigote forms. These antibodies partially inhibit parasite entry into the host cell (Schnaidman et al. 1986, Arruda et al. 1989). A serum against epimastigotes reacts with LPPG (Mendonça-Previato et al. 1983) and immunoprecipitation is abolished when galactofuranose units are oxidized by diluted periodate. Recently, antigal $_{f}$ monoclonal antibodies to a lipid antigen from Paracoccidioides brasiliensis reacted with T. cruzi epimastigotes and Leishmania major promastigotes, confirming the antigenicity of the sugar and previous data showing the existence of $\mathrm{gal}_{f}$ in these parasites (Suzuki et al. 1997).

\section{MUCINS}

Very abundant molecules, presently mainly on the surface of epimastigotes and metacyclic forms, mucins are members of a family of GPI-anchored, heavily O-glycosylated mucin-like glycoproteins (Schenkman et al. 1993, Previato et al. 1994, 1995, Acosta-Serrano et al. 1995). Mucins isolated from epimastigotes and metacyclic trypomastigotes migrate as 35-43 kDa and 35-50 kDa bands in SDSPAGE, respectively (Previato et al. 1985, Yoshida et al. 1989) and as a broad smear (60-200 kDa) when isolated from trypomastigotes (Almeida et al. 1993, 1994). It has been estimated that $3 \times 10^{6}$ mucin molecules are present on the surface of epimastigotes and $1.5 \times 10^{6}$ on metacyclic trypomastigotes. Mucins, are the major substrates of the trans-sialidase, an enzyme secreted into the medium which has been related to the invasion of host cells by the parasite. Heavy glycosylation occurs on serine and threonine through $\mathrm{N}$ acetylglucosamine rather than the common $\mathrm{N}$ acetylgalactosamine. The enzyme involved in biosynthesis of $\mathrm{N}$-acetylglucosamine-linked glycans was recently characterized as a uridine diphospho$\mathrm{N}$-acetylglucosamine: poly peptide-Nacetylglucosaminyltransferase ( $\alpha$-1-O-threonine) present in microsomal membranes (Previato et al. 1998). Structural studies showed that $20 \%$ of the molecules have no other sugar besides the hexosamine, but the majority is biantennary with galactose $(1-4,1-6$ or 1-3, 1-6)-linked to the hexosamine in each ramification. The structures of the oligosaccharide alditols isolated after $\beta$-elimination of the mucins isolated from epimastigotes of the G strain (38/43 kDa) were established by NMR spectroscopy and methylation analysis as in Table II (Previato et al. 1994, 1995, Acosta Serrano et al. 1995).

Sialic acid is added to the mucins by the transsialidase, linking sialic acid ( $\alpha 2-3)$ to terminal $\beta \mathrm{Gal}_{p}$ of the oligosaccharides. Interestingly, no $\mathrm{Gal}_{f}{ }_{f}$ residues were detected in mucins isolated from epimastigotes of the Y strain. Variability in the 
TABLE II

Oligosaccharides from mucins

\begin{tabular}{|c|c|c|}
\hline Oligosaccharitols & epi (\%) & meta $(\%)$ \\
\hline GlcNac-ol & 21 & 22 \\
\hline $\mathrm{Gal}_{f} \beta 1-4 \mathrm{GlcNac}-\mathrm{ol}$ & 8 & 8 \\
\hline $\mathrm{Gal}_{f} \beta 1-4\left(\mathrm{Gal}_{n} \beta 1-6\right) \mathrm{GlcNAc-ol}$ & 15 & 13 \\
\hline $\mathrm{Gal}_{n} \beta 1-3 \mathrm{Gal}_{n}^{p} \beta 1-6\left(\mathrm{Gal}_{f} \beta 1-4\right)$ GlcNAc-ol & 7 & 8 \\
\hline$\left[\left(\mathrm{Gal}_{p} \beta 1-3\right)\left(\mathrm{Gal}_{p} \beta 1-2\right) \mathrm{Gal}_{p} \beta 1-6\right]\left(\mathrm{Gal}_{f} \beta 1-4\right)$ GlcNAc-ol & 17 & 16 \\
\hline$\left[\left(\mathrm{Gal}_{p}^{p} \beta 1-3\right)\left(\mathrm{Gal}_{n}^{p} \beta 1-2\right) \mathrm{Gal}_{n}^{p} \beta 1-6\right]\left(\mathrm{Gal}_{n}^{J} \beta 1-2 \mathrm{Gal}_{f} \beta 1-4\right)$ GlcNAc-ol & 10 & 12 \\
\hline
\end{tabular}

Schenkman et al. 1993, Previato et al. 1994, 1995, Acosta-Serrano et al. 1995.

structure of the O-linked oligosaccharides was found among mucins isolated from different strains of epimastigotes, but not when they were isolated from the same strain (Previato et al. 1994, 1995, Acosta-Serrano et al. 1995). The trypomastigotes also express abundant mucin-like glycoproteins, although apparently larger than the mucins from epimastigotes or metacyclic trypomastigotes (Yoshida et al. 1989, Almeida et al. 1994). The non reducing end of part of the O-linked oligosaccharides have terminal $\alpha$-galactose, a non-substrate for the trans-sialidase. These residues are recognized by antibodies anti-gal present in the serum of chagasic patients a feature that has been used to propose a diagnostic method for Chagas' disease (Almeida et al. 1993, 1994).

Differences in GPI-anchor composition of mucins isolated from epimastigotes, metacyclic trypomastigotes or cell-cultured trypomastigotes were found. Epimastigotes contain only sn-1-alkyl2-acylglycerol, the same lipid found in trypomastigotes, whereas ceramide lipids were found in $70 \%$ of the GPI-mucins isolated from metacyclic forms (Almeida et al. 1994, AcostaSerrano et al. 1995, Heise et al. 1995). Fatty acids of the GPI anchor from trypomastigotes are mostly unsaturated (C18:1, C18:2), in contrast to the saturated fatty acids found in the other stages (C18:0 sphinganine long chain base and mainly $\mathrm{C} 24: 0$ and C16:0 fatty acids). These differences have been related to the synthesis of cytokines by macrophages induced by mucins isolated from trypomastigotes, but not by mucins isolated from epimastigotes (van Voorhis 1992, Silva et al. 1995, Aliberti et al. 1996, Camargo et al. 1997). Unusually the glucosamine was 6-O-substituted with 2aminoethylphosphonate, and 2-aminoethylphosphonate was also present on the third mannose residue distal to glucosamine in the GPI-anchor of the mucin isolated from epimastigotes from the Y strain (Previato et al. 1995).

Interestingly, mucin genes belong to a multigene family, with a minimal number of 484 members per haploid genome (DiNoia et al. 1995, 1998, Salazar et al. 1996, de Freitas et al. 1998). The deduced molecular mass of the core proteins is small (from 17-21 kDa) (DiNoia et al. 1995). The regions encoding the $\mathrm{N}$ and $\mathrm{C}$ termini that contain, respectively, the leader sequence and the membrane anchoring signal are highly conserved, with the central regions which encode the target sites for O-glycosylation showing great variability. The region putatively coding for the N-terminal domain of the mature protein is hypervariable, being different in most of the sequenced transcripts. Gene-specific probes show that the relative abundance of different mRNAs varies within the same parasite clone (DiNoia et al. 1998, Freitas-Junior et al. 1998) Two distinct groups of mucin-like genes were proposed: one group containing $\mathrm{KP}(1-2) \mathrm{T}(6-$ 8 ) repeats, a motif found in mammalian mucins and expressed preferentially in the trypomastigote forms, and the other - expressed in all stages having no repeats with highly variable sequences in the central portion and rich in threonine, proline and serine.

\section{THE Tc-85 GLYCOPROTEIN FAMILY}

\section{Properties of Tc-85}

The existence of at least one important trypomastigote specific surface glycoprotein was inferred when it was observed that antitrypomastigote serum, exhaustively immunoadsorbed with epimastigote forms, was able to immunoprecipitate a protein with a molecular mass of $85 \mathrm{kDa}$ (Zingales et al. 1982). Through systematic studies of lectin binding to the surface of several stages of T. cruzi, Katzin and Colli (1983) found in the trypomastigote form a glycoprotein band of $85 \mathrm{kDa}$ which could be eluted from a WGA-Sepharose column with $0.1 \mathrm{M} \mathrm{N}$-acetil-Dglucosamine. This glycoprotein was named Tc-85 (Katzin \& Colli 1983).

Three monoclonal antibodies that recognized Tc-85 were raised (Alves et al. 1986). These antibodies immunoprecipitated an $85 \mathrm{kDa}$ band which, 
in fact, contained more than one protein, all with the same molecular mass but with different isolectric $\mathrm{pHs}(\mathrm{pH}$ 5.5-9.0) as it could be seen in bidimensional polyacrylamide gels (cf. Andrews et al. 1984). When present in the culture medium these antibodies partially inhibited the internalization of trypomastigote forms in LLC-MK 2 cells (Alves et al. 1986, 1987, Abuin et al. 1989).

Using the monoclonal antibodies it was possible to define some properties of the Tc- 85 protein family (Gonçalves et al. 1991, Abuin et al. 1996a): (1) the molecules are synthesized with a molecular mass of $94 \mathrm{kDa}$; (2) precursor processing is abolished by cysteine-proteases but not by serine-proteases; (3) the half-life of Tc-85 is 3.5-4 $\mathrm{h}$ (Abuin et al. 1996a); (4) the protein (s) expressed on the surface is continuously shed to the culture medium in membrane vesicles, although the phenomenon does not appear to be specific for Tc- 85 since other antigens are also shed through membrane vesiculation (Gonçalves et al. 1991).

The following observations point to the fact that Tc-85 is, in fact, a pool of highly related molecules belonging to the same protein family: (1) the monoclonal antibodies H1A10, H1H8 e 6A2 that recognize only one band in unidimensional gels of tissue culture trypomastigotes of the Y strain are able to immunoprecipitate three bands of 82,78 and 74 $\mathrm{kDa}$ from metacyclic forms of the Y strain or the CL-14 clone obtained from axenic media (Alves et al. 1987, Abuin et al. 1989); (2) monoclonal antibody 6A2 which recognizes Tc-85 in culture trypomastigotes of the Y strain is unable to immunoprecipitate any protein in the YuYu strain, in spite of the fact that this strain contains $85 \mathrm{kDa}$ polypeptides which are recognized by the other two monoclonal antibodies - H1A10 and H1H8. This result can only be explained by a microheterogeneity inside this protein family so that the epitope recognized by the monoclonal antibody 6A2 is absent from the $85 \mathrm{kDa}$ glycoproteins of the $\mathrm{YuYu}$ strain (Alves et al. 1987, Abuin et al. 1989); (3) when the parasites are treated with tunicamycin, monoclonal antibody H1A10 still recognizes a $75 \mathrm{kDa}$ band in unidimensional gels. If the immunoprecipitates are subjected to bidimensional electrophoresis the usual pattern of several proteins with the same molecular mass but distinct pIs appears. These patterns, however, are different when the $\mathrm{Y}$ and YuYu strains are compared, the latter possessing relatively more acidic proteins than those from the Y strain (Abuin et al. 1989).

Taken together, these results strongly suggest the existence of an $85 \mathrm{kDa}$ glycoprotein family whose members should have similar sequences but differing enough depending, at least, on the strain and origin of the trypomastigotes.

\section{The trans-sialidase superfamily}

The existence of sialoglycoconjugates on the surface of $T$. cruzi was established more than 15 years ago. Treatment of the parasites with neuraminidase induced several changes in parasite properties (references in Colli 1993). These and other findings led Previato et al. (1985) to search for alternative pathways of sialic acid incorporation in T. cruzi epimastigote forms. These authors have shown that epimastigotes grown in media containing fetal calf serum contained sialic acid as opposed to parasites grown in the absence of serum. Neuraminidase-treated epimastigotes lost the ability to agglutinate with WGA, known to bind to sialic acid, and acquired the capacity to agglutinate with PNA, a lectin that recognizes galactose (Gal). The incubation of the desyalylated parasites with fetuin (which contains sialic acid) or sialyllactose - but not free sialic acid - restored the WGA receptors (sialic acid) and concomitantly masked the PNA receptors (Gal). The authors proposed that sialylation occurred by trans-glycosylation reactions different from the route in which CMP-sialic acid is the intermediate.

In 1987, Zingales et al. demonstrated for the first time the sialic acid trans-glycosylase activity in trypomastigote forms of T. cruzi. When trypomastigotes were incubated with radioactive fetuin, the label was transferred to sialoglycolipids. Sonicated lysates of trypomastigotes catalyzed labeling of endogenous and exogenous glycoconjugates, the latter belonging to the classes $G_{T}, G_{D}$ and $\mathrm{G}_{\mathrm{M}}$. The activity in the trypomastigote forms was 10-20 fold higher than that found in epimastigotes. These experiments unequivocally demonstrated that sialic acid transfer from fetuin to the glycolipid was not mediated by a pool of free sialic acid but occurred directly from one molecule to the other. The enzyme described in epimastigotes and trypomastigotes was not detected in intracellular amastigotes (Briones et al. 1995).

Schenkman et al. (1991) showed that the specific epitope Ssp-3 from the trypomastigote stage, originally defined by the monoclonal antibody $3 \mathrm{C} 9$ (Andrews et al. 1987) was sialylated. These acceptors of sialic acid correspond to proteins with a high degree of glycosylation having a broad range of molecular masses, now called mucins which were discussed above.

Pereira's group, responsible for the discovery of neuraminidase activity in T. cruzi (Pereira 1983), isolated and sequenced the neuraminidase gene (TCNA) of T. cruzi (Pereira et al. 1991). Parodi et al. (1992) demonstrated that the activities of neuraminidase and trans-sialidase co-precipitated with the same antibody, and Schenkman et al. (1992) unequivocally showed that both activities 
belonged to the same enzyme. Finally, when the deduced amino acid sequence from TCNA was compared with the sequence of SAPA there was $84 \%$ homology corresponding to $93 \%$ of sequence identity in the nucleotide sequence. SAPA (Pollevick et al. 1991) is the "shed acute phase antigen", an immunodominant parasite antigen generating an early humoral response in human acute and congenital infections. That similarity showed that SAPA, neuraminidase and transsialidase are associated to the same enzyme protein (cf. Cross \& Takle 1993, Colli 1993).

The gene of that enzyme displays important characteristics: (1) at least two perfect copies of the consensus sequence (Asp box) found in bacterial neuraminidases are present (Roggentin et al. 1988): Ser-X-Asp-X-Gly-X-Thr-Trp. Bacteria have four consensus sequences; (2) the carboxiterminal sequence is made of 44 repeats of 12 amino acids (TCNA) or 14-47 repeats of the same 12 amino acids (SAPA): -Asp-Ser-Ser-Ala-His[Ser/Gly]-Thr-Pro-Ser-Thr-Pro-[Ala/Val]-; (3) at the carboxi-terminal region, upstream of the repeats there is a sequence common to all members of the family: -Val-Thr-Val-X-Asn-Val-Phe-Leu-TyrAsn-Arg- (see below). This sequence written with the one letter symbol: VTVXNV FLY NR is commonly referred to in our laboratory as the FLY sequence; (4) the carboxi-terminal portion contains a sequence of hydrophobic amino acids typical of
GPI membrane-anchored proteins with the predicted anchor binding site residing 9-12 amino acids upstream the hydrophobic segment.

\section{The Gp-85 glycoprotein family}

The discovery of Tc-85 stimulated several groups to search for the coding genes of that family. Immunoadorbing exhaustively antitrypomastigote serum with epimastigote forms, an approach described by Zingales et al. (1982), was the method employed by these groups to select clones expressing genes coding for proteins compatible with a molecular mass of $85 \mathrm{kDa}$. Some clones have been fully or partially sequenced: TSA1 (Fouts et al. 1991); Tt34c1 (Takle \& Cross 1991); SA85-1.1, 1.2, 1.3 (Kahn et al. 1991) and pTt21 (Takle et al. 1992). After these first disclosures, other groups mentioned in Table III found genes having high degree of homology with the previously cloned sequences. These sequences show $60-70 \%$ sequence identity with TCNA or SAPA and all have the FLY consensus sequence and two non-degenerated Asp boxes. In addition, all have putative glycosylation sites located 9-12 amino acids upstream the hydrophobic sequence at the carboxy terminal end. The members of the Gp- 85 family do not show the repeats in tandem characteristic of TCNA or SAPA and the proteins do not have neuraminidase activity.

To close the circle it would be necessary to show whether the Tc- 85 family, defined to com-

TABLE 1II

Trypomastigote proteins implicated in adhesion or internalization of the parasite into non-phagocytic cells

\begin{tabular}{|c|c|c|c|}
\hline Source & $\begin{array}{l}\text { Antigen } \\
\mathrm{kDa}\end{array}$ & Characteristics & Ref. \\
\hline TCT, MT & 85 & $\begin{array}{l}\text { Precursor of } 95 \mathrm{kDa} \text {; O, N - glycosylation; GPI-anchor; trans-sialidase/gp } \\
85 \text { super-family; binds to laminin }\end{array}$ & $1-7$ \\
\hline TCT & $82-85$ & Glycoprotein, binds to fibronectin and collagen & 8 \\
\hline TCT & 60 & Penetrin, binds heparan sulfate, heparin, collagen & 9,10 \\
\hline TCT & 83 & Glycoprotein, binds to receptors of $74 \mathrm{kDa}$ & 11,12 \\
\hline TCT, MT & $80-220^{a}$ & $\begin{array}{l}\text { Trans-sialidase (neuraminidase) activity; GPI anchor; trans-sialidase/gp } 85 \\
\text { super-family }\end{array}$ & $13-15$ \\
\hline TCT & $?$ & Binds to polypeptides of $32-34 \mathrm{kDa}$ & 16 \\
\hline TCT & $?$ & Binds to $\beta$-adrenergic and muscarinic receptors & 17 \\
\hline TCT & $?$ & Binds to TGF- $\beta$ receptors & 18 \\
\hline TCT, MT & $35-50^{a}$ & Mucins, GPI anchor & $19-21$ \\
\hline MT & 90 & Glycoprotein, GPI anchor, trans-sialidase/gp 85 super-family & $22-25$ \\
\hline MT & 82 & Glycoprotein, GPI anchor, trans-sialidase/gp 85 super-family & 26,27 \\
\hline MT & $68-70^{a}$ & Carbohydrate binding protein ( $\mathrm{Gal}$, Man) to receptors of $58-65 \mathrm{kDa}$ & 28 \\
\hline
\end{tabular}

TCT: tissue culture trypomastigotes; MT: metacyclic trypomastigotes; $a$ : exist also in epimastigote forms; 1 : Abuin et al. 1989; 2: Alves et al. 1986; 3: Couto et al. 1990; 4: Couto et al. 1993; 5: Giordano et al. 1994; 6: Giordano et al. 1999; 7: Katzin \& Colli 1983; 8: Ouaissi 1988; 9: Herrera et al. 1994; 10: Ortega-Barria \& Pereira 1991; 11: Lima \& Villalta 1988; 12: Villalta et al. 1993; 13: Colli 1993; 14: Cross \& Takle 1993; 15: Schenkman et al. 1994; 16: Davis \& Kuhn 1990; 17: von Kreuter \& Santos-Buch 1989; 18: Ming et al. 1995; 19: Ruiz et al. 1993; 20: Schenkman et al. 1993; 21: Yoshida et al. 1989; 22: Franco et al. 1993; 23: Güther et al. 1992; 24: Schenkman et al. 1988; 25: Yoshida et al. 1990; 26: Araya et al. 1994; 27: Ramirez et al. 1993; 28: Bonay \& Fresno 1995. 
prise proteins that bind to WGA and are recognized by monoclonal antibody H1A10, belong or not to the multigenic family described above. In fact, two DNA inserts, a genomic DNA fragment and a full-length cDNA encoding the H1A10 epitope were cloned and characterized. The gene was sequenced with an open reading frame of 2.361 base pairs coding for a protein with an expected molecular mass of 84.549 daltons and $\mathrm{pI}=5.00$. Results showed that both inserts have high sequence identity with all reported members of the Gp85/trans-sialidase gene superfamily. The epitope has been mapped by competition of antibody binding to a Tc-85 recombinant protein with peptides having sequences predicted by the Tc- 85 DNA sequence, which contains also putative $\mathrm{N}$ glycosylation sites and carboxy-terminal GPI anchor insertion sites (Giordano et al. 1999). This gene has $82 \%$ and $62 \%$ sequence identity with SA85-1 (Kahn et al. 1991) and TSA-1 (Fouts et al. 1991), respectively, and contains two non degenerated Asp boxes and the FLY sequence.

\section{The Tc-85 GPI anchor}

Several parasite surface proteins are inserted in the membrane by glycosylphosphatidylinositol showing the motif $\operatorname{Man}(\alpha 1-4) \mathrm{GlcN}(\alpha 1-6) \mathrm{PI}$ containing a non-acetylated glucosamine bound to phosphatidylinositol (cf. McConville \& Ferguson 1993). The presence of a GPI anchor in Tc- 85 was suggested initially by labeling with radioactive palmitic acid. After hydrolysis of Tc-85 with phospholipase $\mathrm{C}$, the lipidic portion was identified as 1-O-hexadecylglycerol and the sugar structure was determined as $\operatorname{Man}(\alpha 1-2) \operatorname{Man}(\alpha 1-6) \operatorname{Man}(\alpha 1-4)$ anhydromannitol (Couto et al. 1993). The fact that Tc-85 labeled with palmitic acid is found in the culture medium suggests that shedding of the glycoprotein occurs without GPI cleavage, contrary to other molecules where anchor cleavage was directly implicated in molecule liberation from the membrane. Shed Tc- 85 could not be hydrolysed by phospholipase $\mathrm{C}$, suggesting a modification at the inositol ring which has been proved to be an esterification by palmitic acid (Abuin et al. 1996b).

\section{The carbohydrates of Tc-85}

The carbohydrates were determined using the fraction of Tc-85 which binds to WGA columns and, thus, containing sialic acid. Alkaline treatment under conditions that liberate $\mathrm{N}$ - and $\mathrm{O}$-glycosydic linkages allowed the separation of two chains. Possibly, there are two O-linked chains made of a mannose disaccharide. The $\mathrm{N}$-glycosidic chains are complex and made of sialic acid, L-fucose, galactose, mannose and $\mathrm{N}$-acetyl glucosamine. The presence of sialic acid was confirmed by hydrolysis with neuraminidase, acid treatment and treatment with sodium periodate and reduction with tritiated borohydride followed by chromatographic detection. The partial structure of the $\mathrm{N}$-glycosydic chain was determined in the oligosacchride which has been liberated from Tc-85 with endo- $\beta-\mathrm{N}$ acetylglucosaminidase $\mathrm{F}$. The sequential treatment of this oligosaccharide with different glycosidases and analysis of the liberated residues allowed to propose the structure of the oligosaccharide bound to the protein as $\operatorname{Man}(\beta 1-4) \operatorname{GlcNAc}(\beta 1-4)$ GlcNAc( $\beta$-Asn). Two mannose residues are bound $\alpha$ (1-6) and a (1-3) to the terminal mannose, forming the anthena and the oligosaccharide $\operatorname{Gal}(\alpha 1-3)$ $\operatorname{Gal}(\beta 1-(4)$ ?) GlcNAc $\beta(1-2)$ Man is bound to one of these mannoses (Couto et al. 1987, 1990). The binding of sialic acid and fucose to that structure has not been determined. The complete determination of the Tc-85 oligosaccharide structure is important to check whether it is or not common to all members (100-1000) of the Gp-85 family. Most probably each protein molecule has more than one oligosaccharide anthena differing in the last sugar residue: some would have $\operatorname{Gal}(\alpha 1-3) \operatorname{Gal}(\beta 1-(4)$ ?) and others sialic acid ( $\alpha 2-3) \mathrm{Gal}(\beta 1-(4)$ ?).

\section{The function of Tc-85}

The trypomastigote form present in the vertebrate host circulation necessarily establishes contacts with structures as basal laminae, extracellular matrices, and cell membranes before invading a vertebrate cell to initiate the parasite intracellular cycle. To understand the invasive process, several laboratories try to identify surface molecules from the trypomastigote forms which could explain adhesiveness and invasiveness. One popular approach uses monoclonal and polyclonal antibodies which may inhibit in vitro cultured cells invasion, followed by molecule identification by immunochemical techniques. Another approach uses affinity chromatography to bind parasite molecules to known host molecules, previously coupled to the affinity resins.

Laminin, a trimer glycoprotein, is an important component of the basal membrane. Different combinations of the $\alpha, \beta$ and $\gamma$ chains allow the construction of the 11 isoforms as yet described. These isoforms have distinct expression patterns even in the same adult individual and very little is known on the specific role of each isoform. As they are difficult to obtain, the majority of the studies are made with laminin from the murine tumor called Engelbreath-Holm-Swarm (EHS), easy to purify in reasonable amounts.

An $85 \mathrm{kDa}$ glycoprotein with $\mathrm{pI}$ ranging from 5.6-6.7 (LBG-laminin binding glycoprotein), present in trypomastigotes (and absent in epimastigotes), binds to columns of laminin- 
Sepharose (Giordano et al. 1994). The binding is independent of the carbohydrates from both molecules and is located in the laminin fragment E8, obtained by treatment of laminin with elastase and described in the literature as a locus for the binding of different cell lineages to laminin. In addition, we have shown that LBG is recognized by monoclonal antibody H1A10, strongly suggesting that at least part of the Tc-85 family members from which LBG is one the most acidic - could be involved in parasite adhesion to the host structures. Radioimmunoassays allowed to determine a number of LBG molecules on the trypomastigote surface seven times less than the total number of molecules recognized by the monoclonal antibody (Giordano et al. 1994). Finally, the protein encoded by the full-lenght cDNA insert that belongs to the Tc-85 family and has a predicted $\mathrm{pI}=5.00$ (LBG) binds to cells and in vitro to laminin, but not to gelatin or fibronectin, in a saturable manner (Giordano et al. 1999). These results pose several immediate questions: would other molecules belonging to the Tc-85 family be involved in adhesion processes to other matrix or membrane elements? What would be the number of family members? Are all members expressed concomitantly on the trypomastigote surface? Does each member possesses specificity of binding to host molecules or are they polyvalent, as other adhesion molecules? It is interesting to remind that the surface of trypomastigotes contains an $85 \mathrm{kDa}$ glycoprotein that binds to fibronectin - a component of the extracellular matrix - a binding dependent on the RGD sequence (Ouaissi 1988). The RGD sequence is present in laminin but is absent from the fragment E8, where LBG binds. Would the fibronectin-binding glycoprotein be a member of the Tc- 85 family?

Other proteins have been related with adhesion to or invasion of host cells by the parasite indicating that most probably, due to the complexity of the system and the variety of environments, the parasite utilizes several molecules to infect the host (Table III). The differential invasive properties among strains (cf. McCabe et al. 1984) and differentiation forms (cf. Hoft 1996), as well as the respective antigens will not be discussed for lack of space but they are listed in Table III.

In order to check the possible host cell membrane receptors for the Tc-85 family members, antiidiotypic antibodies (anti-ID) to purified Fab fragments from monoclonal antibody H1A10 have been prepared. The idea was that part of the antiID antibodies thus obtained would mimic the morphology of the Tc-85 antigen and, thus, help to recognize the receptor in the host cell membrane (Pan et al. 1995). The anti-ID antibodies reacted with with different tissue slices from mice and different cultured cells recognizing three polypeptides (130150,73 and $43 \mathrm{kDa}$ ) on the surface of cultured cells. The inhibition of T. cruzi invasion in cultured cells by the anti-ID antibodies strongly suggest that at least one of these polypeptides could be the receptor for T. cruzi in the host cell (cf. Alves 1996). Which members of the Tc-85 family react with these polypeptides?

In order to answer these and other questions involving the adhesion of T. cruzi to host elements, cloning and expression of different Tc-85 family members and their possible receptors on the host cell membrane are under way.

\section{REFERENCES}

Abuin G, Colli W, de Souza W, Alves MJM 1989. A surface antigen of Trypanosoma cruzi involved in cell invasion (Tc-85) is heterogeneous in expression and molecular constitution. Mol Biochem Parasitol 35: 229-238.

Abuin G, Colli W, Alves MJM 1996a. Turnover and shedding of the Tc-85 surface glycoprotein of Trypanosoma cruzi trypomastigotes. Braz J Med Biol Res 29: 335-341.

Abuin G, Couto AS, de Lederkremer RM, Casal OL, Galli C, Colli W, Alves MJM 1996b. Trypanosoma cruzi: the Tc-85 surface glycoprotein shed by trypomastigotes bears a modified glycosylphosphatidylinositol anchor. Exp Parasitol 82: 290-297.

Acosta-Serrano A, Schenkman S, Yoshida N, Mehlert A, Richardson JM, Ferguson MAJ 1995. The lipid structure of the GPI-anchored mucin-like sialic acid acceptors of Trypanosoma cruzi changes during parasite differentiation from epimastigotes to infective metacyclic trypomastigote forms. J Biol Chem 270: 27244-27253.

Aliberti J, Cardoso M, Martins G, Gazzinelli R, Vieira L, Silva J 1996. Interleukin-12 mediates resistance to Trypanosoma cruzi in mice and is produced by murine macrophages in response to live trypomastigotes. Infect Immun 64: 1961-1967.

Almeida IC, Krautz GM, Kretlli AU, Travassos LR 1993. Glycoconjugates of Trypanosoma cruzi: a $74 \mathrm{kDa}$ antigen specifically reacts with lytic anti $\alpha$-galactosyl antibodies from patients with chronic Chagas disease. J Clin Lab Anal 7:307-316.

Almeida IC, Ferguson MAJ, Schenkman S, Travassos LR 1994. Lytic anti- $\alpha$-galactosyl antibodies from patients with chronic Chagas disease recognize novel O-linked oligosaccharides on mucin-like glycosylphosphatidylinositol-anchored glycoproteins of Trypanosoma cruzi. Biochem J 304: 793-802.

Alves MJM, Colli W 1975. Glycoproteins from Trypanosoma cruzi: Partial purification by gel chromatography. FEBS Lett 52: 188-190.

Alves MJM, da Silveira JF, de Paiva CHR, Tanaka CT, Colli W 1979. Evidence for the plasma membrane localization of carbohydrate-containing macromolecules from epimastigote forms of Trypanosoma cruzi. FEBS Lett 99: 81-85. 
Alves MJM, Abuin G, Kuwajima VY, Colli W 1986. Partial inhibition of trypomastigote entry into cultured mammalian cells by monoclonal antibodies against a surface glycoprotein of Trypanosoma cruzi. Mol Biochem Parasitol 21: 75-82

Alves MJM, Abuin G, Gonçalves MF, Kuwajima VY, Colli W 1987. Heterogeneity of Trypanosoma cruzi surface antigens detected by monoclonal antibodies, p. 323-332 In N Agabian, H Goodman \& N Nogueira (eds), Molecular Strategies of Parasitic Invasion, UCLA Symposia on Molecular and Cellular Biology, New Series, vol. 42, Alan R Liss, New York.

Alves MJM 1996. Members of the Tc- 85 protein family from Trypanosoma cruzi are adhesion proteins. Braz J Med Biol Res 29: 831-833.

Andrews NW, Hong K-S, Robbins ES, Nussenzweig V 1987. Stage-specific surface antigens expressed during the morphogenesis of vertebrate forms of Trypanosoma cruzi. Exp Parasitol 64: 474-484.

Andrews NW, Katzin AM, Colli W 1984. Mapping of surface glycoproteins of $T$. cruzi by two-dimensional electrophoresis: a correlation with the cell invasion capacity. Eur J Biochem 140: 599-604.

Araya JE, Cano MI, Yoshida N, da Silveira JF 1994. Cloning and characterization of a gene for the stagespecific $82-\mathrm{kDa}$ surface antigen of metacyclic trypomastigotes of Trypanosoma cruzi. Mol Biochem Parasitol 65: 161-169.

Arruda MV, Colli W, Zingales B 1989. Terminal $\beta$-Dgalactofuranosyl epitopes recognized by antibodies that inhibit Trypanosoma cruzi internalization into mammalian cells. Eur J Biochem 182: 413-421.

Bonay P, Fresno M 1995. Characterization of carbohydrate binding proteins in T. cruzi. J Biol Chem 270: 11062-11070

Borst P, Fairlamb AH 1998. Surface receptors and transporters of Trypanosoma brucei. Annu Rev Microbiol 52: 745-778.

Briones MRS, Egima CM, Acosta A, Schenkman S 1995. Trypanosoma cruzi trans-sialidase gene lacking Cterminal repeats and expressed in epimastigote forms. Mol Biochem Parasitol 70: 9-17.

Butcher BA, Turco SJ, Hilty BA, Pimenta PF, Panunzio M, Sacks DL 1996. Deficiency in $\beta 1,3$ galactotransferase of Leishmania major lipophosphoglycan mutant adversely influences the Leishmania sand fly interaction. J Biol Chem 271: 20573 20579.

Camargo MM, Almeida IC, Pereira MES, Ferguson MAJ, Travassos LR, Gazzinelli RT 1997. Glycosylphosphatidylinositol-anchored mucin-like glycoproteins isolated from Trypanosoma cruzi trypomastigotes initiate the synthesis of proinflamatory cytikines by macrophages. $J$ Immunol 158: 5890-5901.

Carreira JC, Jones C, Wait R, Previato JO, MendonçaPreviato L 1996. Structural variations in the glycoinositolphospholipids of different strains of Trypanosoma cruzi. Glycoconj J 13: 955-966.

Colli W 1993. Trans-sialidase: a unique enzyme activity discovered in the protozoan Trypanosoma cruzi.
FASEB J 7: 1257-1264.

Couto AS, Katzin AM, Colli W, Lederkremer RM 1987. Sialic acid in a complex oligosaccharide chain of the Tc-85 surface glycoprotein from the trypomastigote stage of Trypanosoma cruzi. Mol Biochem Parasitol 26: 145-154.

Couto AS, Gonçalves MF, Colli W, Lederkremer RM 1990. The N-linked carbohydrate chain of the 85kilodalton glycoprotein from Trypanosoma cruzi trypomastigotes contains sialyl, fucosyl and galactosyl (a1-3) galactose units. Mol Biochem Parasitol 39: 101-110.

Couto A.S, Lederkremer RM, Colli W, Alves MJM 1993. The glycosylphosphatidylinositol anchor of the trypomastigote-specific Tc-85 glycoprotein from Trypanosoma cruzi. Metabolic-labeling and structural studies. Eur J Biochem 217: 597-602.

Cross GAM 1990. Glycolipid anchoring of plasma membrane proteins. Annu Rev Cell Biol 6: 1-39.

Cross GAM, Takle GB 1993. The surface trans-sialidase family of Trypanosoma cruzi. Annu Rev Microbiol 47: 385-411.

Davis CD, Kunh RE 1990. Detection of antigens with affinity for host-cell membrane polypeptides in culture supernatants of Trypanosoma cruzi. Infect Immun 58: 1-6.

DiNoia JM, Sánchez DO, Frasch ACC 1995. The protozoan Trypanosoma cruzi has a family of genes resembling the mucin genes of mammalian cells. J Biol Chem 270: 24146-24149.

DiNoia JM, Pollevick GD, Xavier MT, Previato JO, Mendonça-Previato L, Sánchez DO, Frasch ACC 1996. High diversity in mucin genes and mucin molecules in Trypanosoma cruzi. J Biol Chem 271: 32078-32083.

Di Noia JM, D’Orso I, Aslund L, Sanchez DO, Frasch ACC 1998. The Trypanosoma cruzi mucin family is transcribed from hundreds of genes having hypervariable regions. J Biol Chem 273: 1084310850.

Ferguson MAJ 1997. The surface glycoconjugates of trypanosomatid parasites. Phil Trans $R$ Soc Lond B 352: 1295-1302.

Ferguson MAJ, Allen AK, Snary D 1982. The detection of phosphonolipids in the protozoan Trypanosoma cruzi. Biochem J 207: 171-174.

Franco FRS, Paranhos-Bacalla GS, Yamamuchi, LM, Yoshida N, da Silveira JF 1993. Characterization of a cDNA clone encoding the carboxy-terminal domain of a 90-kilodalton surface antigen of the Trypanosoma cruzi metacyclic trypomastigotes. Infect Immun 61: 4196-4201.

Freire-de-Lima CG, Nunes MP, Corte-Real S, Soares, MP, Previato JO, Mendonça-Previato L, dos Reis GA 1998. Proapoptotic activity of a Trypanosoma cruzi ceramide-containing glycolipid turned on in host macrophages by IFN- $\gamma$. J Immunol 161:49094916.

Freitas-Júnior LHG, Briones MRS, Schenkman S 1998. Two distincts groups of mucin-like genes are differentialy expressed in the developmental stages of Trypanosoma cruzi. Mol Biochem Parasitol 93: 
101-114.

Fouts DL, Ruef BJ, Ridley PT, Wrightsman RA, Peterson DS, Manning JE 1991. Nucleotide sequence and transcription of a trypomastigote surface antigen gene of Trypanosoma cruzi. Mol Biochem Parasitol 46: 189-200.

Giordano R, Chammas R, Veiga SS, Colli W, Alves MJM 1994. An acidic component of the heterogeneous Tc- 85 protein family from the surface of Trypanosoma cruzi is a laminin binding glycoprotein. Mol Biochem Parasitol 65: 85-94

Giordano R, Fouts DL, Tewari D, Colli W, Manning JE, Alves MJM 1999. Cloning of a surface membrane glycoprotein specific for the infective form of Trypanosoma cruzi having adhesive properties to laminin. J Biol Chem 274: 3461-3468.

Golgher DB, Colli W, Souto-Padrón T, Zingales B 1993. Galactofuranose-containing glycoconjugates of epimastigote and trypomastigote forms of Trypanosoma cruzi. Mol. Biochem Parasitol 60: 249-264.

Gomes NA, Previato JO, Zingales B, Mendonça-Previato L, dos Reis GA 1996. own-regulation of T lymphocyte activation in vitro and in vivo induced by glycoinositolphospholipids from Trypanosoma cruzi - Assignment of the T cell-supressive determinant to the ceramide domain. J Immunol 156: 628-635.

Gonçalves MF, Umezawa ES, Katzin AM, de Souza W, Alves MJM, Zingales B, Colli W 1991. Trypanosoma cruzi: shedding of surface antigens as membrane vesicles. Exp Parasitol 72: 43-53.

Gorin PAJ, Barreto-Bergter EM, da Cruz FS 1981. The chemical structure of the D-galacto-D-mannan component of Trypanosoma cruzi -C13-NMR shift dependence on structure of D-galactose to D-mannose linkage. Carbohydr Res 88: 177-188.

Güther MLS, Cardoso de Almeida ML, Yoshida N, Ferguson MAJ 1992. Structural studies on the glycosylphosphatidylinositol membrane anchor of Trypanosoma cruzi 1G7-antigen. J Biol Chem 267: 6820-6828.

Heise N, Cardoso de Almeida ML, Ferguson MAJ 1995. Characterization of the lipid moety of the glycosylphosphatidylinositol anchor of Trypanosoma cruzi 1G7-antigen. Mol Biochem Parasitol 70: 71-84.

Herrera EM, Ming M, Ortega-Barria E, Pereira, MEA 1994. Mediation of Trypanosoma cruzi invasion by heparan sulfate receptors on host cells and penetrin counter-receptors on the trypanosomes. Mol Biochem Parasitol 65: 73-83.

Hoft DF 1996. Differential mucosal infectivity of different life stages of Trypanosoma cruzi. Am J Trop Med Hyg 55: 360-364.

Kahn S, Colbert TG, Wallace JC, Hoagland NA, Eisen $\mathrm{H}$ 1991. The major $85-\mathrm{kDa}$ surface antigen of the mammalian-stage forms of Trypanosoma cruzi is a family of sialidases. Proc Natl Acad Sci USA 88: 4481-4485.

Katzin AM, Colli W 1983. Lectin receptors in Trypanosoma cruzi: an N-acetyl-D-glucosamine-containing surface glycoprotein specific for the trypomastigote stage. Biochim Biophys Acta 727: 403-411.

Koplin R, Brisson JR, Whitfield C 1997. UDP- galactofuranose precursor required for formation of lipopolysaccharide 0 antigen of Klebsiella pneumoniae serotype 01 is synthesized by the product of the RFBD (KP01) gene. J Biol Chem 272: 4121-4128.

Lederkremer RM, Alves MJM, Fonseca GC, Colli W 1976. A lipopeptidophosphoglycan from Trypanosoma cruzi (epimastigota): Isolation, purification and carbohydrate composition. Biochim Biophys Acta 444: 85-96.

Lederkremer RM, Tanaka CT, Alves MJM, Colli W 1977. Lipopeptidophosphoglycan from Trypanosoma cruzi. Amide and ester-linked fatty acids. Eur J Biochem 74: 263-267.

Lederkremer RM, Casal OL, Tanaka CT, Colli W 1978. Ceramide and inositol content of the lipopeptidophosphoglycan from Trypanosoma cruzi. Biochem Biophys Res Commun 85: 1268-1274.

Lederkremer RM, Casal OL, Alves MJM, Colli W 1980. Evidence for the presence of D-galactofuranose in the Lipopeptidophosphoglycan from $T$. cruzi. Modification and tritium labeling. FEBS Lett 116: 25-29.

Lederkremer RM, Casal OL, Alves MJM, Colli W 1985a. Trypanosoma cruzi: aminoacid and phosphorus linkages in the lipopeptidophosphoglycan. Biochem Int 10: 89-96.

Lederkremer RM, Casal OL, Couto A, Colli W 1985b. Structural studies of the oligosaccharide moiety of the lipopeptidophosphoglycan from Trypanosoma cruzi. Eur J Biochem 151: 539-542.

Lederkemer RM, Lima C, Ramirez MI, Casal OL 1990. Structural features of the pipopetidophosphoglycan from Trypanosoma cruzi common with the glycosylphosphatidylinositol anchors. Eur J Biochem 192: 337-345.

Lederkremer RM, Lima C, Ramirez MI, Ferguson MA, Homans, SW, Thomas-Oates J 1991. Complete structure of the glycan of lipopeptidophosphoglycan from Trypanosoma cruzi epimastigotes. J Biol Chem 266: 23670-23675.

Lederkremer RM, Lima CE, Ramirez MI, Gonçalves MF, Colli W 1993. Hexadecylpalmitoylglycerol or Ceramide is linked to similar Glycophosphoinositol Anchor-like structures in Trypanosoma cruzi. Eur J Biochem 218: 929-936.

Lederkremer RM, Colli W 1995. Galactofuranose-containing glycoconjugates in trypanosomatids. Glycobiology 5: 547-552.

Lima MF, Villalta F 1988. Host cell attachment by Trypanosoma cruzi-identification of an adhesion molecule. Biochem Biophys Res Commun 155: 256-262.

McCabe RE, Remington JS Araújo FG 1984. Mechanisms of invasion and replication of the intracellular stage in Trypanosoma cruzi. Infect Immun 46: 372-376.

McConville MJ, Bacic A, Mitchell GF, Handman E 1987. Lipophosphoglycan of Leishmania major that vaccinates against cutaneous leishmaniasis contains an alkylglycerophosphoinositol lipid anchor. Proc Natl Acad Sci USA 84: 8941-8945.

McConville MJ, Homans SW, Thomas-Oates JE, Dell A, Bacic A 1990. Structures of the glycoinositol- 
phospholipids from Leishmania major. J Biol Chem 265: 7385-7394.

McConville MJ, Ferguson MAJ 1993. The structure, biosynthesis and function of glycosylated phosphatidylinositols in the parasitic protozoa and higher eukaryotes. Biochem J 294: 305-324.

Mendelzon DH, Parodi AJ 1986. N-linked high mannose-type oligosaccharides in the protozoa Crithidia fasciculata and Crithidia harmosa contain galactofuranose residues. J Biol Chem 261: 21292133.

Mendelzon DH, Previato JO, Parodi AJ 1986. Characterization of protein-linked oligosaccharides in trypanosomatid flagellates. Mol Biochem Parasitol 18: 355-367.

Mendonça-Previato L, Gorin PAJ, Braga AF, Scharfstein J, Previato JO 1983. Chemical structure and antigenic aspects of complexes obtained from epimastigotes of Trypanosoma cruzi. Biochemistry 22: 4980-4987.

Merello S, Xavier MT, Parodi AJ 1995. The presence of galactofuranose and ribose units in asparagine-linked oligosaccharides of the digenetic trypanosomatid Endotrypanum schaudinni. Mol Biochem Parasitol 69: 73-79.

Ming M, Ewen ME, Pereira MEA 1995. Trypanosome invasion of mammalian cells require activation on the TGFß signaling pathway. Cell 82: 287-296.

Moraes CT, Bosch M, Parodi AJ 1988. Structural characterization of several galactofuranose-containing, high-mannose-type oligosaccharides present in glycoproteins of the trypanosomatid Leptomonas samueli. Biochemistry 27: 1543-1549.

Nassau PM, Martin SL, Brown RE, Weston A, Monsey D, McNeil MR, Duncan K 1996. Galactofuranose biosynthesis in Escherichia coli $\mathrm{K}-12$ : identification and cloning of the UDP-galactopyranose mutase. $J$ Bacteriol 178:1047-1052.

Ortega-Barria E, Pereira MEA 1991. A novel T. cruzi heparin-binding protein promotes fibroblast adhesion and penetration of engineered bacteria and trypanosomes into mammalian cells. Cell 67: 411-421.

Ouaissi MA 1988. Role of the RGD sequence in parasite adhesion to host cells. Parasitol Today 46: 169173.

Pan Y, Yuhasz SC, Amzel LM 1995. Antiidiotypic antibodies-biological function and structural studies. FASEB J 9: 43-49.

Parodi AJ, Pollevick GD, Mautner M, Buschiazzo A, Sanches DO, Frasch ACC 1992. Identification of the gene (s) coding for trans-sialidase of Trypanosoma cruzi. EMBO J 11: 1705-1710.

Pereira MEA 1983. A developmentally regulated neuraminidase activity in Trypanosoma cruzi. Science 219: 1444-1446.

Pereira MEA, Santiago-Mejia J, Ortega-Barria E, Matzilevich D, Prioli RP 1991. The Trypanosoma cruzi neuraminidase contains sequences similar to bacterial neuraminidases, to YWTD repeats of the LDL receptor and to type III modules of fibronectin. J Exp Med 174: 179-192.

Pimenta PFP, Saraiva EMB, Rowton E, Modi GB,
Garraway, Beverley SM, Turco SJ, Sacks DL 1994. Evidence that the vectorial competence of phlebotomine sand flies for different species of Leishmania is controlled by structural polymorphisms in the surface lipophosphoglycan. Proc Natl Acad Sci USA 91: 9155-9159.

Pollevick GD, Affranchino JL, Frasch ACC, Sánchez DO 1991. The complete sequence of a shed acute phase antigen of Trypanosoma cruzi. Mol Biochem Parasitol 47: 247-250.

Previato JO, Andrade AFB, Pessolani MCV, MendonçaPreviato L 1985. Incorporation of sialic acid into Trypanosoma cruzi macromolecules. A proposal for a new metabolic route. Mol Biochem Parasitol 16: 85-96.

Previato JO, Gorin PAJ, Mazurek M, Xavier MT, Fournet B, Wieruszesk JM, Mendonça-Previato L 1990. Primary structure of the oligosaccharide chain of lipopeptidophosphoglycan of epimastigote forms of Trypanosoma cruzi. J Biol Chem 265: 2518-2526.

Previato JO, Mendonça-Previato L, Jones C, Wait R, Fournet B 1992. Structural characterization of a novel class of glycophospholipids from the protozoan Leptomonas samueli. J Biol Chem 267: 24279 24286.

Previato JO, Mendonça-Previato L, Jones C, Wait R 1993. Structure of the carbohydrate moiety of the glycophosphosphingolipid of Endotrypanum schaudinni. Glycoconjugate J 10: 340.

Previato JO, Jones C, Gonçalves LBP, Wait R, Travassos LR, Mendonça-Previato L 1994. O-glycosidically linked $\mathrm{N}$-acetylglucosamine-bound oligosaccharides from glycoproteins of Trypanosoma cruzi. Biochem J 301:151-159.

Previato JO, Jones C, Xavier MT, Wait R, Travassos LR, Parodi AJ, Mendonça-Previato L 1995. Structural characterization of the major glycosylphosphatidylinositol membrane-anchored glycoprotein from epimastigote forms of Trypanosoma cruzi Y-strain. J Biol Chem 270: 7241-7250.

Previato JO, Jones C, Wait R, Routier F, Saraiva E, Mendonça-Previato L 1997. Leishmania adleri, a lizard parasite, express structurally similar glycoinositolphospholipids to mammalian Leishmania. Glycobiology 7: 687-695.

Previato JO, Sola-Penna M, Agrellos OA, Jones C, Oeltmann T, Travassos LR, Mendonça-Previato L 1998. Biosynthesis of O-N-acetylglucosamine: polypeptide- $\mathrm{N}$-acetylgucosaminyltransferase- catalyzing formation of $\mathrm{N}$-acetylglucosamine $\alpha-1-\mathrm{O}$ threonine. J Biol Chem 273: 14982-14988.

Ramirez MI, Ruiz R, Araya J.E, da Silveira JF, Yoshida $\mathrm{N}$ 1993. Involvement of the stage-specific 82 kilodalton adhesion molecule of Trypanosoma cruzi metacyclic trypomastigotes in host cell invasion. Infect Immun 61: 3636-3641.

Roggentin P, Rothe B, Lottspeich F, Schauer R 1988. Cloning and sequencing of a Clostridium perfringens sialidase gene. FEBS Lett 238: 31-44.

Ruiz R, Rigoni VL, Gonzalez J, Yoshida N 1993. The $35 / 50 \mathrm{kDa}$ surface antigen of Trypanosoma cruzi metacyclic trypomastigotes, an adhesion molecule 
involved in host cell invasion. Parasite Immunol 15: 121-125.

Salazar NA, Mondragon A, Kelly JM 1996. Mucin-like glycoprotein genes are closely linked to members of the trans-sialidase super-family at multiple sites in the Trypanosoma cruzi genome. Mol Biochem Parasitol 76: 91-103.

Schenkman S, Yoshida N, Cardoso de Almeida ML 1988. Glycophosphatidylinositol-anchored proteins in metacyclic trypomastigotes of Trypanosoma cruzi. Mol Biochem Parasitol 29: 141-152.

Schenkman S, Jiang M-S, Hart GW, Nussenzweig V 1991. A novel cell surface trans-sialidase of Trypanosoma cruzi generates a stage-specific epitope required for invasion of mammalian cells. Cell 65 : 1117-1125.

Schenkman S, Pontes de Carvalho L, Nussenzweig V 1992. Trypanosoma cruzi trans-sialidase and neuraminidase activities can be mediated by the same enzymes. J Exp Med 175: 567-575.

Schenkman S, Ferguson MAJ, Heise H, Cardoso de Almeida ML, Mortara RA, Yoshida N 1993. Mucin-like glycoproteins linked to the membrane by glycosyl-phosphatidylinositol anchor are the major acceptors of sialic acid in a reaction catalysed by trans-sialidase in metacyclic forms of Trypanosoma cruzi. Mol Biochem Parasitol 59: 293-304.

Schenkman S, Eichinger D, Pereira MEA, Nussenzweig V 1994. Structural and functional properties of the Trypanosoma cruzi trans-sialidase. Annu Rev Microbiol 48: 499-523.

Schnaidman BB, Yoshida N, Gorin PAJ, Travassos LR 1986. Cross reactive polysaccharides from Trypanosoma cruzi and fungi (especially Dactylium dendroides). J Protozool 33: 186-191.

Silva J, Vespa G, Cardoso M, Aliberti J, Cunha F 1995. Tumor necrosis factor a mediates resistance to Trypanosoma cruzi infection in mice by inducing nitric oxide production in infected $\mathrm{g}$ interferon-activated macrophages. Infect Immun 63: 4862-4867.

Suzuki E, Toledo ES, Takahashi HE, Straus AH 1997. A monoclonal antibody directed to terminal residue of $\beta$-galactofuranose of a glycolipid antigen isolated from Paracoccidioides brasiliensis: cross-reactivity with Leishmania major and Trypanosoma cruzi. Glycobiology 7: 463-468.

Takle GB, Cross GAM 1991. An 85 kDa surface antigen gene family of Trypanosoma cruzi encodes polypeptides homologous to bacterial neuraminidases. Mol Biochem Parasitol 48: 185-198.

Takle GB, O’Connor J, Young A, Cross GAM 1992. Sequence homology and absence of mRNA defines a possible pseudogene member of the Trypanosoma cruzi gp85/sialidase multigene family. Mol Biochem Parasitol 56: 117-128.

Tetaud E, Barrett MP, Bringaud F, Baltz T 1997. Kinetoplastid glucose transporters. Biochem J 325: 569-580.

Travassos LR, Almeida IC 1993. Carbohydrate immunity in American trypanosomiasis. Springer Semin Immun 15: 183-204.

Turco SJ, Orlandi PA, Homans SW, Ferguson MAJ, Dwek RA, Rademacher TW 1989. Structure of the phosphosaccharide-inositol core of Leishmania donovani lipophosphoglycan. J Biol Chem 264: 6711-6715.

Turco SJ, Descoteaux A 1992. The lipophosphoglycan of Leishmania parasites. Annu Rev Microbiol 46: 6594.

Van Voorhis WC 1992. Coculture of human peripheral blood mononuclear cells with Trypanosoma cruzi leads to proliferation of lymphocytes and cytokine production. J Immunol 148: 239-248.

Villalta F, Ruiz-Ruano A, Valentine AA, Lima MF 1993. Purification of a 74-kilodalton surface glycoprotein from heart myoblasts that inhibits binding and entry of Trypanosoma cruzi into heart cells. Mol Biochem Parasitol 61: 217-230.

von Kreuter B, Santos-Buch CA 1989. Modulation of Trypanosoma cruzi adhesion to host muscle membranes by ligands of muscarinic cholinergic and beta adrenergic receptors. Mol Biochem Parasitol 36: 41-50.

Weston A, Stern RJ, Lee RE, Nassau PM, Monsey D, Martin SL, Scherman MS, Besra GS, Duncan K, McNeil MR 1998. Biosynthetic origin of mycobacterial cell wall galactofuranosyl residues. Tub Lung Diseas 78: 123-131.

Yoshida N, Mortara RN, Araguth MF, Gonzalez JC, Russo, M 1989. Metacyclic neutralizing effects of the monoclonal 10D8 directed to the 35- and 50kilodalton surface glycoconjugates of Trypanosoma cruzi. Infect Immun 57: 1663-1667.

Yoshida N, Blanco SA, Araguth MF, Russo M, González J 1990. The stage-specific 90-kilodalton surface antigen of metacyclic trypomastigotes of Trypanosoma cruzi. Mol Biochem Parasitol 39: 39-46.

Zingales B, Andrews NW, Kuwajima VY, Colli W 1982. Cell surface of Trypanosoma cruzi: possible correlation with the interiorization process in mammalian cells. Mol Biochem Parasitol 6: 111-124.

Zingales B, Carniol C, Lederkremer RM, Colli W 1987. Direct sialic acid transfer from a protein donor to glycolipids of trypomastigote forms of T. cruzi. $\mathrm{Mol}$ Biochem Parasitol 26: 135-144. 